VOX PATRUM 33 (2013) t. 59

Sławomir WYSZOMIRSKI*

\title{
POTRAWY NA UCZCIE NAZYDIENA (HORATIUS, SATURAE II 8) A DE RE COQUINARIA APICJUSZA
}

Od wielu lat w Polsce i na świecie zauważa się ożywienie badań nad antyczną sztuką kulinarną. Informacji na jej temat dostarcza nam nie tylko dziełko Apicjusza, pt. De re coquinaria, ale także literatura agronomiczna, sympotyczna (np. Uczta Filoksenosa ${ }^{1}$ ), czy też rozmaite leksykony. Wykorzystuje się także luźne wzmianki rozsiane w różnych dziełach autorów greckich i rzymskich pisanych prozą bądź wierszem. Badania te ważne dla poznania upodobań kulinarnych świata grecko-rzymskiego, są także bardzo istotne dla lepszego zrozumienia między innymi utworów poetyckich sięgających po tematykę sympotyczną, na przykład po niektóre Satyry Horacego. Dzięki nim czytając dzisiaj utwory tego poety nikt już nie powinien pomylić rokietki siewnej, zwanej popularnie rukolą (eruca = Brassica eruca L.), z brukwią, jak to mamy w przekładzie Jana Czubka ${ }^{2}$, czy też w polskich komentarzach do Satyr Horacego Renaty Körner ${ }^{3}$ i Oktawiusza Jurewicza ${ }^{4}$. Podobnie nikt też nie powinien już brać kapusty polnej czyli brzoskwi (rapulum = Brassica rapa L.) za rzodkiew $^{5}$, pasternaku zwyczajnego (siser = Pastinaca sativa L.) za sałatę polną 6 ,

* Dr hab. Sławomir Wyszomirski, prof. UMK - kierownik Katedry Filologii Klasycznej na Wydziale Filologicznym Uniwersytetu Mikołaja Kopernika w Toruniu; e-mail: slawomir.wyszomirski@umk.pl.

${ }^{1}$ Przykładem zainteresowań literaturą sympotyczną w Polsce może być najnowsza książka Magdaleny Stuligrosz, , Uczta” Filoksenosa na tle tradycji greckiej poezji gastronomicznej, Poznań 2012. Warty przypomnienia jest też przekład Sztuki rybołówstwa Owidiusza przygotowany przez Aleksandra Mikołajczaka, w którym tłumacz dokonuje identyfikacji różnych gatunków ryb poławianych i wykorzystywanych w kuchni rzymskiej (Publiusz Owidiusz Naso, Sztuka rybołówstwa, Tekst łaciński do druku przygotował, przekładu na język polski dokonał oraz komentarzami opatrzył A.W. Mikołajczak, Gniezno 1997).

${ }^{2}$ Por. Horatius, Saturae II 8, 51, thum. J. Czubek, w: Horacy, Wybór poezji, oprac. J. Krókowski, Wrocław - Warszawa - Kraków - Gdańsk 1971, 254-258.

${ }^{3}$ R. Körner, Komentarz do wyboru poezji Q. Horatiusa Flaccusa, Lwów 1938, 642 (komentarz do Satirae II, w. 51).

${ }^{4}$ Por. Kwintus Horacjusz Flakkus, Dzieła wszystkie, II: Gawędy, Listy, Sztuka poetycka, tekst łaciński do druku przygotował, wyboru przekładów dokonał, komentarzem opatrzył O. Jurewicz, Wrocław 1988, 240 (nota do Saturae II, w. 51).

${ }^{5}$ Por. Körner, Komentarz do wyboru poezji, s. 635 (komentarz do Saturae II, w. 8); Kwintus Horacjusz Flakkus, Dzieła wszystkie, II, , s. 234, przypis do Saturae II, w. 8.

${ }^{6}$ Por. Körner, Komentarz do wyboru poezji, s. 636 (komentarz do Saturae II, w. 9). 
ani też sosu rybnego zwanego allec za pastę lub za „majonez bądź proszek z wnętrzności ryb morskich, może podobny do kawioru"8. W każdym razie w badaniach nad kuchnią grecką i rzymską dokonano tak dużych postępów, iż w znacznej mierze komentarze do tych utworów Horacego, które poruszają tematykę kulinarną i sympozjalną, należałoby napisać na nowo.

Utwory Horacego pozwalają nam śledzić upodobania gastronomiczne Rzymian okresu augustowskiego oraz dostarczają cennego materiału porównawczego, który umożliwia odpowiedź na pytanie, czy z biegiem czasu gusta kulinarne mieszkańców imperium rzymskiego ulegały zmianom, a jeśli tak, czy były to zmiany znaczące czy też niewielkie. Wydaje się, iż najlepszym i najbardziej naturalnym punktem odniesienia w tego rodzaju badaniach porównawczych może być tutaj De re coquinaria, ponieważ: po pierwsze, dziełko Apicjusza dostarcza najobszerniejszego materiału; po drugie, jego autor był najprawdopodobniej starszy od Horacego o jedno pokolenie lub niewiele więcej - jak się przypuszcza, Apicjusz urodził się około roku 25 przed Chr. ${ }^{9}$ W swoim porównaniu ograniczę się tutaj do jednego utworu Horacego, a mianowicie Satyry 8 z księgi II, nazywanej niekiedy Ucztą Nazydiena.

W satyrze tej Fundaniusz składa Horacemu relację z biesiady, na którą został zaproszony Mecenas przez dorobkiewicza Nazydienusa Rufusa. Towarzyszyli mu, oprócz Fundaniusza, jeszcze dwaj inni poeci, tj. Wariusz i Wiskus. Gospodarz przygotował niezwykle wyszukane potrawy. Nie poprzestał jednak na serwowaniu dań, które wnosili niewolnicy, lecz zaczął wygłaszać własne komentarze na temat podawanych potraw, już to dla podkreślenia wystawności uczty, już to dla popisania się wiedzą kulinarną. Zachowanie Nazydiena wzbudziło wśród zaproszonych gości z jednej strony niesmak, z drugiej złośliwe komentarze i kpiny. Kiedy w końcu na ucztujących spadał z łoskotem baldachim zawieszony nad sufitem, i kiedy po usunięciu skutków katastrofy wniesiono kolejne dania, zniesmaczone towarzystwo szybko opuściło gospodarza rezygnując z dalszej degustacji. Jak łatwo zauważyć, satyra Horacego stała się pierwowzorem Uczty Trymalchiona w Satyrikonie Petroniusza.

W satyrze tej Horacy kilkakrotnie daje opis dań, którymi uraczono gości. Po raz pierwszy czyni to w wersach 6-17, kiedy na stół jako przystawkę postawiono dzika schwytanego, jak twierdził gospodarz, przy łagodnym wietrze południowym w Lukanii, który był garnirowany warzywami mającymi pobudzić żołądek, takimi jak: kapusta polna (rapulum), sałata siewna (lactuca), rzepa (radix), pasternak zwyczajny (siser), i który został polany sosem rybnym zwanym allec oraz fekulą sprowadzoną z wyspy Kos (faecula Coa). Na ucztach rzymskich potrawę z dzika zwykle podawano jako danie główne, tutaj natomiast jako przystawkę, gdyż gospodarz pragnął podkreślić wystawność uczty,

\footnotetext{
${ }^{7}$ Por. Kwintus Horacjusz Flakkus, Dzieła wszystkie, II, s. 235 (przypis do Saturae II, w. 9).

${ }^{8}$ R. Körner, Komentarz do wyboru poezji, s. 636 (komentarz do Saturae II, w. 9).

${ }^{9}$ Por. S. Wyszomirski, Wstęp, w: Apicjusz, O sztuce kulinarnej ksiag dziesięć, Tekst, przekład i komentarz I. Mikołajczyk - S. Wyszomirski, Toruń 2012, 6nn.
} 
która zresztą rozpoczyna się de medio die, a więc od wczesnego popołudnia, a nie - jak to było w zwyczaju - dopiero po zachodzie słońca. Wydaje się, iż w porównaniu z zaleceniami Apicjusza, dzik Nazydiena został przyrządzony w sposób dosyć prosty. U Apicjusza oczywiście nie ma mowy o warzywach, które mają pobudzić apetyt biesiadników, gdyż zwykle dzik stanowił danie główne, a nie przystawkę. Podaje on natomiast dwa przepisy na jego przygotowanie. W pierwszym mowa jest o dziku pieczonym, którego najpierw myje się gąbką, posypuje solą i utartym kminem rzymskim, a następnie pozostawia na jedną dobę. Następnego dnia wstawia się go do pieca. Po upieczeniu polewa się go sosem sporządzonym z utartego pieprzu z condimentum aprunum, a więc ze specjalnych przypraw do dzika, najprawdopodobniej korzennych, następnie $\mathrm{z}$ miodu $\mathrm{z}$ liquamen, gotowanego moszczu winnego (caroenum) oraz wina z rodzynek (passum) ${ }^{10}$. Drugi przepis podaje sposób przygotowania dzika gotowanego w wodzie morskiej z dodatkiem gałązek lauru. Po ugotowaniu ściąga się z niego skórę i podaje z solą, gorczycą i octem ${ }^{11}$. Najwyraźniej jednak według Apicjusza o smaku potrawy z dzika decyduje nie jego wstępna „obróbka”, tj. to, czy został on upieczony czy ugotowany, lecz sos, którym został on polany. Stąd też w księdze VIII daje on szereg wyszukanych przepisów na sosy, które mogą być podawane do dzika czy to pieczonego czy to gotowanego, na gorąco lub na zimno ${ }^{12}$. Sos, którym został polany dzik Nazydiena, nie jest z pewnością wyszukany. Jest nim przede wszystkim sos rybny allec, wytwarzany z resztek pozostałych przy produkcji sosu rybnego zwanego liquamen, a więc był on od tego ostatniego sosem gorszej jakości i tańszym ${ }^{13}$. Być może w swoim opisie Horacy wymienia nazwę tego sosu celowo, chcąc podkreślić niekompetencję i nieuzasadnione samochwalstwo gospodarza, który sili się na znawcę kuchni rzymskiej i bogacza, w rzeczywistości zaś proponuje gościom tanie zamienniki. Podobnie jest z kolejną przyprawą podaną do dzika, a mianowicie z fekulą z wyspy Kos (faecula Coa). Tłumacze i współcześni komentatorzy Horacego sądzą, iż chodzi tutaj o osad winny z wina produkowanego na wyspie Kos $^{14}$, który ma kwaśny smak. Badacze ci nie znają jednak

${ }^{10}$ Por. Apicius, De re coquinaria VIII 1, 1. W niniejszym artykule posługiwano się wydaniem krytycznym przygotowanym przez M.E. Milham: Apicii decem libri qui dicuntur de re coquinaria et excerpta a Vinidario conscripta, Lipsiae 1969.

${ }^{11}$ Por. tamże VIII 1, 2.

${ }^{12}$ Por. tamże VIII 1, 3-9.

${ }^{13}$ Por. Cassianus Bassus, Geoponica XX 46, 1-4, thum. I. Mikołajczyk: Kassianus Bassus, Geoponika. Bizantyńska encyklopedia rolnicza, Toruń 2012, 398: „Tak zwane liquamen produkuje się w ten sposób. Do garnka wrzuca się rybie wnętrzności i zasypuje solą. Również drobne ryby, przede wszystkim smugoboki, małe barweny, małe szprotki, sardele albo małe ryby. Wszystko soli się jednakowo i wystawia na słońce, często nimi potrząsając. Kiedy przeleżały w soli przez lato, produkuje się z nich garum w ten sposób. Do garnka wypełnionego wyżej wspomnianymi rybami wkłada się gęsto upleciony koszyk, przez który cedzi się garum. Ta część płynna, która przefiltruje się przez koszyk, nazywa się liquamen. Masę, która pozostała, nazywa się allec".

${ }^{14}$ Adolf Kiessling w komentarzu do: Q. Horatius Flaccus, Satiren, Berlin 1959, s. 276-277 (Sa- 
przekazu Izydora z Sewilli, który podaje, iż fekulę otrzymywano w wyniku gotowania dorodnych winogron do momentu, aż osiągnęły one konsystencję miodu, a następnie schładzano ją. Była ona dobra na żołądek, a więc również pobudzała apetyt ${ }^{15}$. Często mieszano ją $\mathrm{z}$ sosem rybnym allec, tak jak podobnie czyniono to częstokroć z sosem liquamen, do którego dodawano miód lub miód pitny. Wynika zatem z tego, iż dzik Nazydiena został polany tanim sosem rybnym allec zmieszanym z zamiennikiem miodu lub miodu pitnego, otrzymywanym z winogron. Do tak przygotowanej potrawy z dzika Nazydien zaproponował gościom cenione wino albańskie i falerneńskie.

Następnie przystąpiono do uczty właściwej (w. 25-32, 42-53). Podano na niej potrawy z ptaków, skorupiaków i ryb, które dzięki odpowiednim przyprawom i zabiegom kulinarnym nie przypominały w smaku dań znanych dotąd wszystkim. Horacy więcej uwagi poświęca potrawom z ryb. Dowiadujemy się, że kucharz Nazydiena przygotował ilia passeris et rhombi, a więc jakieś danie z wnętrzności, być może z ikry, ryby zwanej turbotem (lub skarpem - Psetta maxima L.) oraz z ryby zwanej gładzicą lub płastugą (Pleuronectes rhombus L.), a więc $z$ ryb należących do rodziny flądrowatych. Tych Mecenas nie odważył się spróbować. Potem zaserwowano rybę murenę obłożoną rawkami, do przyprawienia której przygotowano specjalny sos. Do jego sporządzenia użyto oliwy z pierwszego tłoczenia pochodzącej z Venafrum - miasteczka leżącego w Kampanii, następnie sosu rybnego zwanego garum wyprodukowanego $\mathrm{z}$ makreli w Hiszpanii. To wszystko gotowano po dodaniu wina - najpierw miejscowego pięcioletniego, a następnie importowanego z Chios - oraz białego pieprzu, z niewielką ilością octu winnego, którego nadmiar mógłby popsuć smak sosu. Apicjusz w De re coquinaria nie podaje osobnych przepisów na przyrządzanie ryb takich jak turbot lub gładzica. Jednakże z myślą o nich podaje przepisy na sosy, które mają zastosowanie do wszelkiego rodzaju ryb smażonych, pieczonych lub gotowanych w wodzie ${ }^{16}$. Inaczej jest w przypadku ryb bardziej cenionych, do których zaliczał węgorza morskiego zwanego też kongerem, brzanę morską, tuńczyka, strzępiela, makrelę, rybę piłę, złotopstrąga, karmazyna, węgorza ${ }^{17}$ i przede wszystkim murenę. Apicjusz podaje osobne przepisy na przygotowanie dla nich odpowiednich sosów, w tym także trzy dla mureny pieczonej i trzy dla mureny gotowanej w wodzie ${ }^{18}$. Ich stałym składnikiem jest pieprz, oliwa, miód, liquamen, ocet, lubczyk ogrodowy, zaś w przeważającej części także wino. Odróżniają je od siebie inne dodatki, ta-

turae II 4, w. 73) oraz s. 336-337 (Saturae II 8, w. 9) zarówno pod pojęciem faecula Coa jaki i faex rozumie wysuszone sproszkowane drożdże.

${ }^{15}$ Por. Isidorus Hispalensis, Etymologiae XX 3, 13, ed. J. Oroz Reta M.A. Marcos Casquero: San Isidoro de Sevilla, Etymologías, Edicion bilingüe, II, Madrid 1983, 592: „Faecula uva pinguis, decocta usque ad crassitudinem mellis, ac refrigata, utilis stomacho".

${ }^{16}$ Por. Apicius, De re coquinaria X 1, 1-8; X 2, 8-9 i 17-18.

${ }^{17}$ Por. tamże X 1, 9. 11-14; X 2, 10-16; X 3, 1-2.

${ }^{18}$ Por. tamże X 2, 1-6. 
kie jak cząber ogrodowy, wytłoki szafranu, śliwki damasceńskie bez pestek, gotowany moszcz winny (defritum), kocimiętka właściwa, koper ogrodowy, nasiona selera, sumak garbarski, daktyle caryota, gorczyca, kmin zwyczajny, kmin rzymski, kolendra, suszona mięta, orzeszki piniowe. W porównaniu do zaleceń Apicjusza sos do mureny, którym przechwala się Nazydien, wydaje się mało atrakcyjny, gdyż zawiera on jedynie podstawowe składniki stosowane w kuchni rzymskiej, a jego wartość ma podnosić obecność w nim drogiego importowanego wina $\mathrm{z}$ Chios. Ale czy rzeczywiście jego sos do mureny był tak prosty? Po opisie głównych składników owego sosu Nazydien wypowiada słowa, które dotąd większość tłumaczy oraz autorów komentarzy nie wiąże z poprzednimi (a moim zdaniem powinni), a mianowicie:

„Erucas viridis, inulas ego primus amaras

monstravi incoquere; illotos Curtillus echinos, ut melius muria quod testa marina remittat" ${ }^{\prime 19}$.

„Ja pierwszy zaleciłem, by zieloną rokietkę siewną (rokulę) i gorzki oman wielki (Inula Helenium L.) gotować, (tzn. tak jak pierwszy) Kurtilliusz zalecił, by gotować jeże morskie na sucho (tj. bez wody), ponieważ od (takiego, tj. gotowanego $\mathrm{z}$ wodą) sosu lepsze jest to, co wydziela się z morskich skorupiaków (tj. ze wszelkich stworzeń morskich posiadających skorupę, jak jeże morskie, małże, ślimaki, itp.)" ${ }^{\prime 20}$.

Jest oczywiste, że w wersach tych Nazydien przechwala się swoim wynalazkiem kulinarnym, który polega na tym, iż pierwszy zaczął gotować rokietkę

${ }^{19}$ Horatius, Saturae II 8, w. 51-53, ed. Jurewicz, II, s. 241.

${ }^{20}$ Tamże, thum. własne; por. wybrane przekłady polskie: 1) tłum. P. Popiel: Satyry i listy Horacego, I: Satyry, Kraków 1903, 221: „Pierwszym zieloną rzeżuchę i gorzki pasternak nauczył, I Razem gotować, Kurtillus nie wypłukanych jeżowców, / Użył, bo sok, co ten ślimak wypuszcza jest w gruncie najlepszym"; 2) tłum. M. Motta: Horacego ody, epody, satyry i listy, Poznań 1896, 173: „Ja pierwszy / także dowiodłem, iż rukiew trzeba z omanem gotować, / nie płukanych zaś jeży użył w to miejsce Kurtiljus, / ślimak ten bowiem sok puszcza lepszy od słonych rosołów"; 3) thum. J. Czubek, w: Horacy, Wybór poezji, oprac. J. Krókowski, s. 257, lub w: Kwintus Horacjusz Flakkus, Dzieła wszystkie, II, s. 240: „Z brukwią mieszać zieloną i gorzkim omanem / Jam kazał pierwszy, Kurtyl z jeżem niepłukanem, / Że lepszy sok puszcza samaż małża słona”; 4) tłum. M. Matuszewicz: Satyry wszystkie Horacyusza wierszem polskim przez jednego z obywatelow litewskich wyłożone, Wilno 1784, 260: „Którą poliwkę gdy z nas każdy jedząc chwalił, / Gospodarz trwogę o wino, i by mógł skojarzyć / Lepszą myśl, jął się chlubić, że on najprzód warzyć / I zieloną gorczycę, i gorzkie omany / Rozkazał, na żołądek zdrowo obetkany, / Mówił, że i Kurtyllus z Epikura szkoły / Najpierwszy jeże morskie płatając na poły / Nieoskrobane z łuski same warzyć kazał, / I to jako Filozof na oko pokazał, / Że i więcej rosołu i lepszego jeże / Nieskrobane dać mogą, niż ostrygi świeże"; 5) tłum. J. Sękowski: Horacy, Satyry, Warszawa 1972, 92: „Stwierdziłem, że gotując brukwi bulwy świeże / Z omanem i dodając niepłukane jeże / Uzyska się soczystsze niż ostryga danie"; zob. też niemiecki przekład O. Schönbergera: Horaz, Satiren und Episteln. Auf Grundlage der Übersetzung von J.K. Schönberger, Berlin 1976, 145: „Ich war der erste, der lehrte, grünes Senfkraut und bitteren Alant darunterzukochen, Curtillus lehrte, nichtgewässerte Seeigel hindeinzukochen, weil der Saft, den dieses Schaltier des Meeres liefert, besser sei als Fischlake". 
siewną z omanem wielkim. Ale po co? Przecież te dwie rośliny, ugotowane razem, nie składały się na jakąś nową potrawę! Musiały być zatem dodane do przygotowywanego sosu do mureny. I tutaj niewątpliwie sos ów był nowością, gdyż także i później do sosu do tej ryby nie dodawano nigdy rokietki siewnej (rukoli) ani omanu. U Apicjusza rokietka siewna pojawia się rzadko, raz jako składnik sosu do tępogłowa solonego ${ }^{21}$, innym razem do sosu z kaczki i z żurawia $^{22}$, kiedy indziej jako składnik soli ziołowej na wszystko ${ }^{23}$. Raz też jest mowa o zastosowaniu soku $\mathrm{z}$ rokietki jako dodatku do gotowanych bulw ${ }^{24}$ i raz o jej nasionach obecnych w sosie do dzika ${ }^{25}$. Natomiast o omanie wielkim (inula) nie ma u Apicjusza mowy wcale, jeśli nie liczyć wzmianki w Apici excerpta a Vinidario viro inlustri ${ }^{26}$, gdzie jest wymieniany jako jedna z przypraw, którą musi mieć pod ręką zapobiegliwy kucharz. Wynika więc z tego, iż sos Nazydiena mógł wzbudzić wśród gości duże zaciekawienie, chociaż czy spełniał ich oczekiwania i czy był smaczny, tego się nie dowiadujemy, tym bardziej, że mowę gospodarza przerwał nieoczekiwany wypadek, kiedy to na ucztujących gości spadł rozwieszony pod sufitem baldachim.

Po przywróceniu porządku wniesiono kolejne dania: porcjowanego żurawia pieczonego w mące i posypanego solą, następnie wątróbki z białej gęsi tuczonej figami, łapy zajęcze, które, jak zaznaczono, są delikatniejsze od combra, dalej kosy, z przypaloną, jak ironicznie zauważa poeta, piersią, a na koniec dzikie gołębie $\mathrm{z}$ obciętymi kuprami. W tym zestawie dominowały potrawy z drobiu, a wyjątkiem są łapy, czy też dolne partie kończyn zająca. Przepisu na to danie Apicjusz nie podaje, chociaż potrawom z zająca poświęca wiele miej$\mathrm{sca}^{27}$. Między innymi znajdujemy u niego przepisy na zająca faszerowanego, zająca $\mathrm{w}$ sosie własnym lub korzennym, zająca posypanego suchym pieprzem, czy też przepis na pulpety z zająca, oraz wiele innych. Osobną księgę (VI) Apicjusz poświęca potrawom z drobiu. Znajdujemy tam oczywiście zalecenia na przygotowanie dań z dzikich gołębi a zwłaszcza z żurawia, a ponieważ ptak ten stanowił przysmak Rzymian, przepisy te są bardzo wyszukane i opisane obszerniej niż inne. Może wydawać się, że na ich tle pieczony żuraw z uczty Nazydiena został przyrządzony w sposób bardzo prosty, ale trzeba pamiętać, iż poeta daje nam tutaj skróconą charakterystykę potrawy, opisując jedynie wzrokowe wrażenia biesiadników, którzy znudzeni komentarzami gospodarza zbierają się właśnie do wyjścia.

$\mathrm{Na}$ osobną uwagę zasługuje tutaj informacja o wątróbkach z białej gęsi tuczonej figami. Przepisu na tę potrawę nie odnajdujemy w De re coquinaria

\footnotetext{
${ }^{21}$ Por. Apicius, De re coquinaria IX 10, 7.

${ }^{22}$ Por. tamże VI 2, 6.

${ }^{23}$ Por. tamże I 13, 1.

${ }^{24}$ Por. tamże VII 12, 3.

${ }^{25}$ Por. tamże VIII $1,8$.

${ }^{26}$ Por. Apici excerpta a Vinidario viro inlustri, w: Apicius, De re coquinaria, dz. cyt., s. 87.

${ }^{27}$ Por. Apicius, De re coquinaria VIII 8, 1-13.
} 
Apicjusza. Jednak z relacji Pliniusza dowiadujemy się, że to właśnie Apicjusz wynalazł nowy sposób przyrządzania wątróbki gęsiej. Polegał on na tym, że ptaki te przed zabiciem były karmione suszonymi figami. Ten sposób postępowania zapewniał odpowiedni smak gęsim wątróbkom, do których następnie dodawano wina z miodem (mulsum) ${ }^{28}$. Tymczasem w świetle informacji Horacego, której nie można podważyć, zwyczaj tuczenia gęsi figami, był znany jeszcze przed Apicjuszem. A ponieważ w oparciu zachowane przekazy dotyczące życia Apicjusza trudno jest stwierdzić, że żył on w czasach Horacego, wydaje się konieczne skorygować relację Pliniusza i rozumieć ją w ten sposób, iż innowacja Apicjusza polegała jedynie na podawaniu wątróbek z dodatkiem wina z miodem (mulsum), a nie na tuczeniu gęsi figami, gdyż ta praktyka była stosowana już dużo wcześniej.

Na zakończenie należy postawić pytanie, co wynika z porównania kuchni Apicjusza z potrawami serwowanymi na uczcie Nazydiena? Omówiona tutaj satyra Horacego jest dla nas dowodem na to, iż już w czasach augustowskich rozwijanie sztuki kulinarnej miało swoje grono zwolenników i że kucharze starali się zaskoczyć nowymi pomysłami uczestników sympozjonów, co skłaniało ich do ciągłego eksperymentowania na tym polu. Przykładem takich dążeń jest między innymi sposób przyrządzenia sosu, którym została polana murena Nazydiena, czy chociażby dzikie gołębie, którym ucięto kupry. Z drugiej strony, na przykładzie De re coquinaria, można zauważyć ewolucję sztuki kulinarnej, która przykłada coraz większą wagą do różnego rodzaju przypraw mających zastosowanie w coraz bardziej wyszukanych sosach, które nadawały właściwy smak rozmaitym potrawom z ryb, drobiu i zwierzyny łownej. Wreszcie porównania te przyczyniają się do lepszego zrozumienia tekstów samego Horacego, pozwalają chociażby dostrzec ironię poety tam, gdzie dotąd nawet się jej nie domyślano. Sądzę, że tego typu badania warto kontynuować w przyszłości.

DISHES AT NASIDIEN'S FEAST (HORATIUS, SATURAE II 8) AND APICIUS' DE RE COQUINARIA

\section{(Summary)}

Two issues were raised in the article entitled „Dishes at Nasidien's feast (Horatius, Saturae II 8) and Apicius' De re coquinaria”. First, comparison of dishes the description of which Horace included in Saturae II 8 with heir analogical recipes for these from Apicius' De re coquinaria. These comparisons lead to the conclusion that, even in Augustan times, developing the culinary art had its supporters and that the chefs were trying to surprise symposium participants with

${ }^{28}$ Por. Plinius, Historia naturalis VIII 209, ed. C. Mayhoff: C. Plini Secundi Naturalis Historiae, Bd. 2, Lipsiae 1909, 151 „Adhibetur et ars iecori feminarum sicut anserum, inventum M. Apici, fico arida saginatis ac satie necatis repente mulsi potu dato". 
new ideas, which made them experiment in this area all the time. An example of such efforts, among the others, is the method of making a sauce which was used to put on Nasidien's moray, or wild pigeons whose croups had been cut off. On the other hand, on the example of De re coquinaria we can observe the evolution of culinary art which attached more and more importance to various kinds of spices used in more and more sophisticated sauces which gave a proper taste to diverse dishes of fish, poultry and game. The other issue, which is still present, is proper understanding and interpretation of these fragments of Horace's Saturae II 8 where the poet gives us a description of dishes prepared by Nasidien's chefs. Among the others, attention was drawn to the fact that the notion of faecula Coa (Saturae II. 8. 9) shall not be understood, as assumed before, as dried powdered yeast or wine grounds but rather as a substitute for grape honey described by Isidor (Etymologiae XX 3, 13: „Faecula uva pinguis, decocta usque ad crassitudinem mellis, ac refrigata, utilis stomacho"). This understanding of faecula Coa lets us read differently 6-9 verses in Saturae II 8 where the wild boar served by Nasidien was poured over by cheap substitutes, i.e. so called allec sauce (instead of liquamen) and faecula Coa (instead of honey). The Horace's description, thus, has, in this place an ironic implication. It was also suggested that the 51-53 verses in Saturae II 8, where Nasidien boasts that he was the first one with the idea of boiling eruca sativa (rucola) with inula helenium, should be linked with previous verses which give the description of the sauce used for pouring over moray as eruca sativa boiled with inula helenium did not form a new dish but it was an ingredient of the mentioned sauce. Information about liver of a white goose fed with figs in Saturae II 8, 88 deserves special attention. We cannot find this dish recipe in Apicius' De re coquinaria. However, we learn from the Plinius' account that it was Apicius who invented a new method of preparing goose liver (Plinius, Historia naturalis VIII 209: Adhibetur et ars iecori feminarium sicut anserum, inventum M. Apici, fico arida saginatis ac satie necatis repente mulsi potu dato). This method involved feeding those birds with figs before they were killed. This way ensured that goose liver had a right taste and later wine with honey was added to it. However, according to Horace's information, which cannot be shaken, the custom of feeding geese with figs had been known before Apicius. As, on the basis of preserved records on Apicius' life, it is difficult to confirm that he lived in Horace's times it seems necessary to correct the account of Pilnius and to interpret it in the way that the innovation of Apicius involved only serving liver with some wine with honey (muslum), not feeding geese with figs as this practice had been done much earlier.

Słowa kluczowe: potrawy, uczta Nazydiena, Horacy, Apicjusz

Key words: dishes, Nasiden's Feast, Horatius, Apicius 